\title{
Multi-Refinement Effect of Rare Earth Lanthanum on $\alpha-A 1$ and Eutectic Si Phase in Hypoeutectic Al-7Si Alloy
}

\author{
Xiaoyan $\mathrm{Wu}^{1}$, Huarui Zhang ${ }^{2, *(1)}$, Haitao Jiang ${ }^{1}$, Zhenli Mi ${ }^{1}$ and Hu Zhang ${ }^{2}$ \\ 1 Institute of Engineering Technology, University of Science and Technology Beijing, Beijing 100083, China; \\ wuxiaoyan@ustb.edu.cn (X.W.); jianght@ustb.edu.cn (H.J.); mizl@nercar.ustb.edu.cn (Z.M.) \\ 2 School of Materials Science and Engineering, Beihang University, Beijing 100191, China; \\ zhanghu@buaa.edu.cn \\ * Correspondence: huarui@buaa.edu.cn; Tel.: +86-10-82319256; Fax: +86-10-82338598
}

Received: 17 April 2020; Accepted: 7 May 2020; Published: 11 May 2020

\begin{abstract}
The effect of La addition on primary $\alpha-\mathrm{Al}$ and the eutectic Si phase of Al-7Si alloy is investigated systematically in this work. The results indicate that La addition causes a multi-refining efficiency on the microstructure of Al-7Si alloy, including refinement of $\alpha$-Al grains and secondary dendrite arm spacing as well as eutectic Si particles. The grain size, secondary dendrite arm spacing and area of eutectic Si particles are decreased by $26.8 \%, 7.7 \%$ and $26.7 \%$, respectively, with the addition of $0.1 \mathrm{wt} . \% \mathrm{La}$. It is also found that La-rich phases of $\mathrm{Al}_{2} \mathrm{Si}_{2} \mathrm{La}$ form and distribute in the vicinity of the eutectic $\mathrm{Si}$ phase. The crystal structure and lattice parameter of $\mathrm{Al}_{2} \mathrm{Si}_{2} \mathrm{La}$ phase are determined to be hexagonal $(\mathrm{a}=\mathrm{b}=0.405 \mathrm{~nm}, \mathrm{c}=6.944 \mathrm{~nm})$ based on the TEM analysis results. The multi-refinement effects are mainly attributed to the increased constitutional undercooling caused by the low solubility of $\mathrm{La}$ in $\mathrm{Al}$ alloy and the growth-restricting factor caused by the $\mathrm{Al}_{2} \mathrm{Si}_{2} \mathrm{La}$ phase.
\end{abstract}

Keywords: Al-7Si alloy; La element; multi-refinement; microstructure; $\mathrm{Al}_{2} \mathrm{Si}_{2} \mathrm{La}$ phase

\section{Introduction}

Al-7Si alloys have been extensively used in die casting to produce components that comply with the mechanical performance of lightweight structures, environmental and other requirements. The mechanical properties of hypoeutectic Al-7Si cast alloy are controlled by the casting process, heat treatment process and physical metallurgy, such as chemical composition and microstructural features [1-5]. Tensile properties, particularly ductility, are accepted to be mainly controlled by microstructural features, normally the morphology and size of the $\alpha$-Al primary phase, silicon particles and other precipitate phases which may be present in the microstructure [6]. Many efficient methods have been proposed to refine the primary $\alpha$-Al phase and modify eutectic Si particles in order to improve the mechanical properties of the alloy. Micro-alloying additions such as refinement Ti, B $[7,8]$ and modifier $\mathrm{Sr}, \mathrm{Na}[9,10]$ have been proven to be efficient.

Recently, considerable interest has been focused on the use of rare earth elements such as La, Ce, Sc, $\mathrm{Yb}, \mathrm{Er}$, Eu, etc., which have multiple effects including melt purification, grain refinement and eutectic Si modification in Al-Si alloys. Many authors [11-17] have verified the refinement and modification effects of $\mathrm{Yb}, \mathrm{Er}, \mathrm{Sc}$ and Sm elements on Al-Si alloys in corresponding research. The refinement mechanism regarding grain size is attributed to heterogeneous nucleation. The modification effect on eutectic Si particles is based on the widely accepted impurity-induced twinning (IIT) mechanism theory, which has been proven by Lu and Hellawell [18]. They proposed that a growth twin was created at the interface when the ratio (the atomic radius of the modification elements relative to that of 
$\mathrm{Si}$ ) was close to 1.646. However, they also proposed that a ratio of 1.646 was the principal requirement for a modifying agent. According to the investigation of Li et al. [19], the $\mathrm{Yb}$ element refined rather than modified the eutectic $\mathrm{Si}$ in hypoeutectic Al-Si alloys, though Yb possessed a favorable atomic radius ratio $\left(\mathrm{r}_{\mathrm{Yb}} / \mathrm{r}_{\mathrm{Si}}=1.646\right)$ for the IIT mechanism. Li et al. also reported [20] that Eu was the only rare earth element modifying the eutectic Si phase. Thus far, the theory used to interpret the effect of rare earth elements on Al-7Si alloys remains controversial.

As the least expensive rare earth element, La has the potential to replace the precious elements mentioned above. Pourbahari et al. [21] have explored the effects of different La content on the structure and mechanical properties of Al-7Si alloy, finding that the optimal La addition content was $0.1 \mathrm{wt} . \%$. However, the refinement or modification mechanism of La on microstructure remains unclear. In addition, there is no clear explanation for the large amount of La-rich intermetallics formed in the Al-7Si alloy.

In the present study, the influence of rare earth $0.1 \mathrm{wt} . \%$ La on the microstructure of cast Al-7Si alloy was systematically investigated. Electron probe microanalysis (EPMA) and TEM measurements were used to analyze the La-rich intermetallics and elucidate the multi-refinement mechanism of La in terms of dendrite structure and Si particles.

\section{Experimental Procedure}

Commercial Al-7Si alloy was used as the base alloy for the castings. According to our former experiment and other reports in [21-23], the optimal rare earth addition content in cast aluminum alloys is $0.1 \mathrm{wt} . \%$. The main focus of the present paper was on the Al-7Si alloy with $0.1 \mathrm{wt} . \% \mathrm{La}$ addition. The alloys studied in this work were prepared using Al-7Si alloy and Al-20La master alloy through a low-pressure die casting process. The chemical compositions of castings were monitored by direct reading spectrometry (Thermo ARL EasySpark, ARL, WA, USA), and the results are given in Table 1. After casting, some castings were tested in the as-cast condition, and the rest were subjected to T6 heat treatment. The castings were solution treated in an accurate electrical furnace at $535^{\circ} \mathrm{C}$ for $4 \mathrm{~h}$, quenched in warm water at $80^{\circ} \mathrm{C}$ and finally aged at $170{ }^{\circ} \mathrm{C}$ for $8 \mathrm{~h}$.

Table 1. Chemical composition of Al-7Si-xLa casting alloy (wt.\%).

\begin{tabular}{cccccc}
\hline Alloy & Si & Mg & Fe & La & Al \\
\hline Al-7Si & 7.15 & 0.436 & 0.114 & - & Bal. \\
Al-7Si-0.1La & 7.13 & 0.442 & 0.116 & 0.1 & Bal. \\
\hline
\end{tabular}

Optical microscopy (OM), scanning electron microscopy (SEM), EPMA and TEM equipped with an energy dispersive spectrometer (EDS) detector were employed to characterize the microstructure of Al-7Si alloys with and without La addition. Samples for OM investigations were ground, polished and etched using $0.5 \% \mathrm{HF}$ solution. The same samples used for OM investigations were further analyzed using EPMA element mapping on a JXA8230 (JEOL, Tokyo, Japan) equipped with a wavelength dispersive spectrometer (WDS). The specimens for TEM investigations were mechanically ground, polished and dimpled to $30 \mu \mathrm{m}$, then ion-beam milled using a Gatan Precision Ion Polishing System (PIPS, Gatan Model 691, Gatan, Pleasanton, CA, USA). TEM observations were performed on a JEOL-2100F TEM (JEOL, Tokyo, Japan) at $200 \mathrm{kV}$. Electron backscatter diffraction (EBSD) analysis was completed on a Zeiss Auriga field emission SEM (Carl Zeiss, Yarra, Germany) fitted with an EBSD detector. Each sample was scanned at a tilt angle of $70^{\circ}$ to the detector. A step size of $5 \mu \mathrm{m}$ at $140 \times$ magnification was used for crystallographic texture and grain morphology analyses. Finally, the Image-Pro Plus software (IPP 6.0, IPWIN Applicaton, Inc., Rrockville, MD, USA) was used to measure the characteristics (aspect ratio, Feret diameter and area) of eutectic Si particles and to monitor the refinement effect of La (Figure 1). 

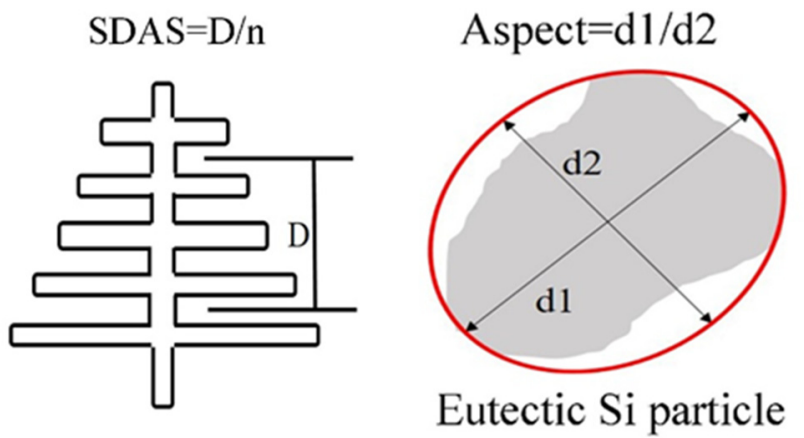

Figure 1. Schematic representation of the calculation of secondary dendrite arm spacing (SDAS) and aspect ratio of eutectic Si particles.

\section{Results and Discussion}

\subsection{Microstructure}

Figure 2a,b shows the representative microstructures of Al-7Si alloy and Al-7Si-0.1La alloy observed by $\mathrm{OM}$, and their corresponding microstructures at the T6 heat-treated state are presented in Figure 3. In the as-cast alloy without La (Figure 2a), the eutectic Si particles presented acicular-like shapes with a large size, low roundness and high area. With the addition of $0.1 \mathrm{wt} . \% \mathrm{La}$, the refined eutectic Si particles presented a fragmented shape and a slight decrease in the $\mathrm{Si}$ particle size was achieved, as shown in Figure 2b. It is evident in Figure 3 that the addition of $0.1 \mathrm{wt} . \%$ La could refine the eutectic Si particles. To study the effects of $0.1 \mathrm{wt} . \%$ La on the level of refinement observed in the microstructures, the aspect ratio, Feret diameter and area of eutectic Si particles were chosen as indicative parameters of the evolution extent of the Si particles, and the results are shown in Table 2. Rod-like eutectic Si particles with the Feret diameter of $7.42 \mu \mathrm{m}$ and area of $14.47 \mu^{2}$ were found in the Al-7Si alloy. While, for the alloy with $0.1 \mathrm{wt} . \% \mathrm{La}$, the average area of eutectic silicon decreased significantly to $10.61 \mu \mathrm{m}^{2}$, which was about $26.7 \%$ less than the untreated alloy. However, the aspect ratio of eutectic $\mathrm{Si}$ in the Al-7Si alloy with addition was similar (about 2.5) to that of the unrefined alloy. All these results illustrate that the rare earth element La had the effect of refining the eutectic Si particles.

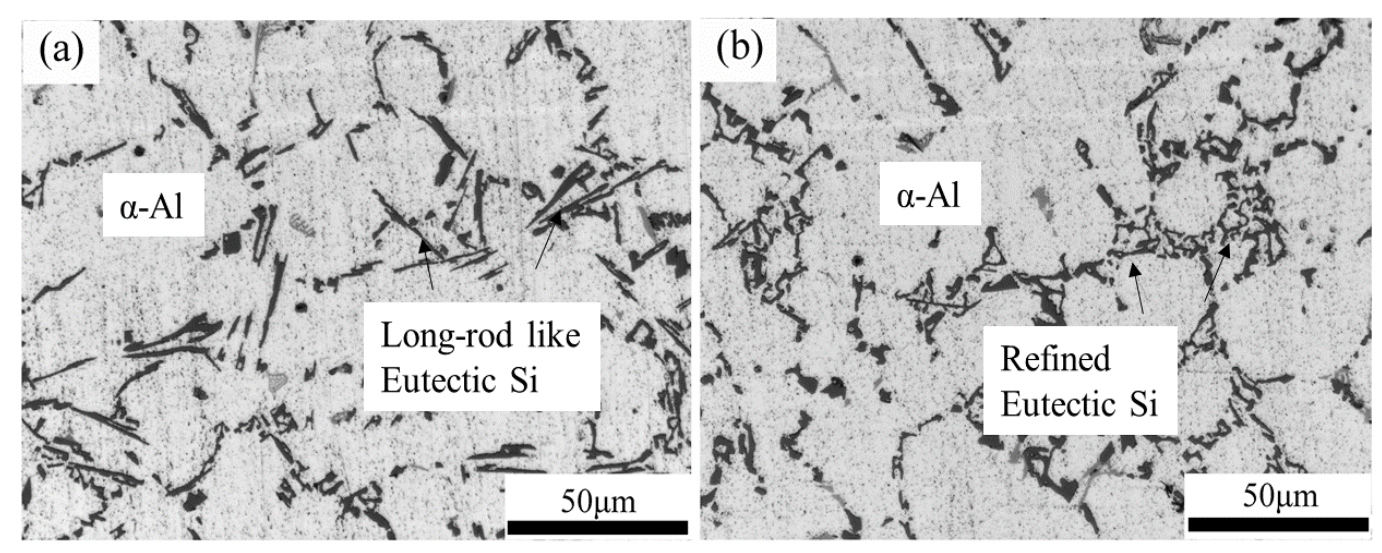

Figure 2. Representative eutectic structure observed by optical microscopy $(\mathrm{OM})$ at low magnification taken from as-cast alloys: (a) Al-7Si alloy; (b) Al-7Si-0.1La alloy. 


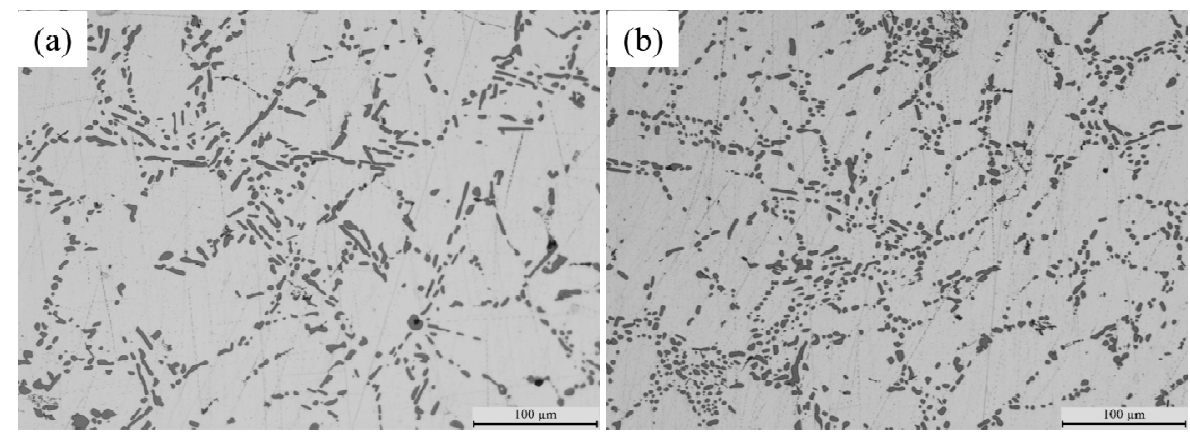

Figure 3. Representative eutectic structure observed by OM taken from T6 heat-treated alloys: (a) Al-7Si alloy; (b) Al-7Si-0.1La alloy.

Table 2. The size of eutectic Si particles.

\begin{tabular}{ccc}
\hline Alloy & Al-7Si Alloy & Al-7Si-0.1La Alloy \\
\hline Aspect ratio & $2.44 \pm 0.27$ & $2.47 \pm 0.37$ \\
Feret diameter $(\mu \mathrm{m})$ & $7.42 \pm 1.17$ & $4.46 \pm 0.57$ \\
Area $\left(\mu \mathrm{m}^{2}\right)$ & $14.47 \pm 2.45$ & $10.61 \pm 1.02$ \\
\hline
\end{tabular}

The refinement effect of La addition on $\alpha$-Al grains and dendrite structure on T6 heat-treated Al-7Si alloys is presented in Figure 4. The quantitative changes of SDAS and $\alpha$-Al grain size of the studied alloys as calculated by IPP 6.0 software are depicted in Table 3 . The coarse microstructures with large secondary dendrite arm spacing $(20.26 \mu \mathrm{m})$ and coarse $\alpha$-Al grain size $(242.38 \mu \mathrm{m})$ are obvious in Figure $4 \mathrm{a}, \mathrm{b}$ for the Al-7Si alloy without La addition. As Figure 4c,d clearly illustrates, with a small addition of $0.1 \mathrm{wt} . \% \mathrm{La}$, the microstructures were refined, and the SDAS and $\alpha$-Al grain size were decreased to $18.66 \mu \mathrm{m}$ and $177.45 \mu \mathrm{m}$, respectively. Considering the above analysis, the rare earth element La was a somewhat effective refiner, which presented the multi-refining effect on eutectic $\mathrm{Si}$ particles, $\alpha-\mathrm{Al}$ grains and dendrite structure.
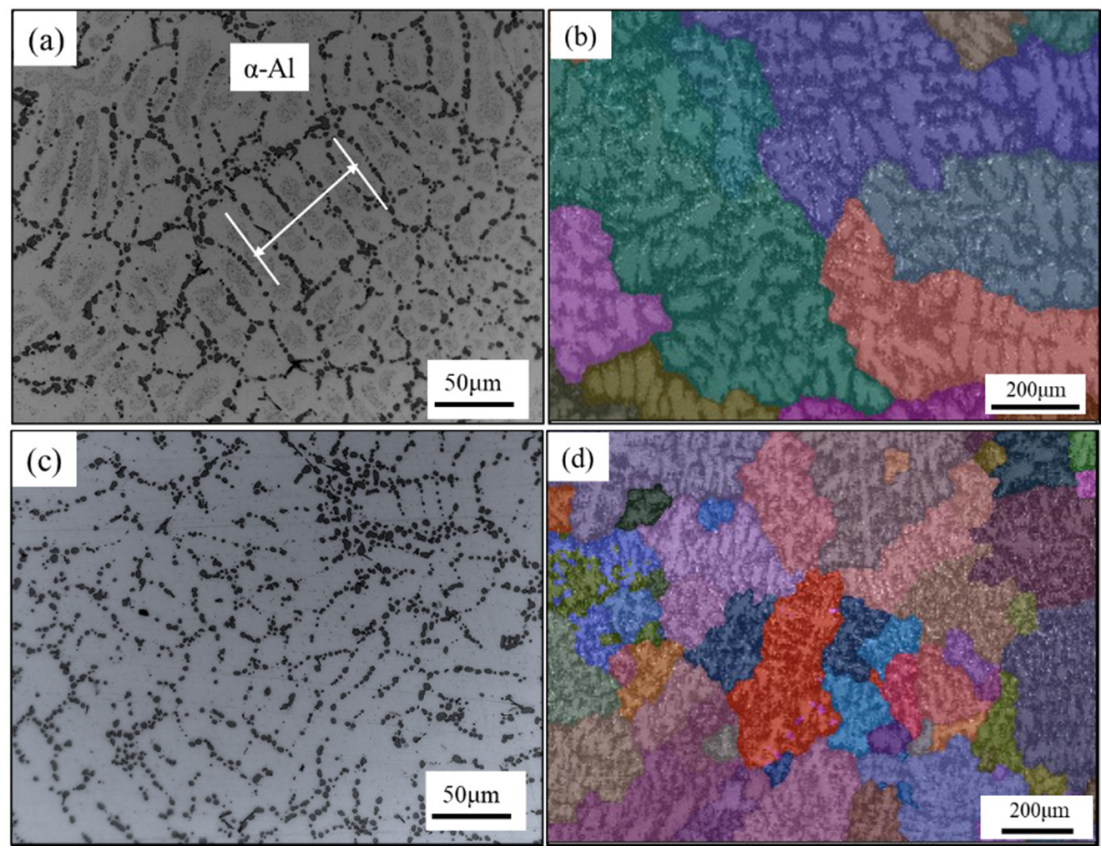

Figure 4. Representative dendritic structure (obtained by $\mathrm{OM}$ ) and grain microstructure (obtained by electron backscatter diffraction (EBSD)) of T6 heat-treated alloys: (a,b) Al-7Si alloy; (c,d) Al-7Si-0.1La alloy. 
Table 3. SDAS and grain size of Al-7Si-xLa alloy.

\begin{tabular}{ccc}
\hline Samples & SDAS $(\mu \mathrm{m})$ & Grain Size $(\mu \mathrm{m})$ \\
\hline Al-7Si & $20.26 \pm 3.22$ & $242.38 \pm 21.95$ \\
Al-7Si-0.1La & $18.66 \pm 1.85$ & $177.45 \pm 18.32$ \\
\hline
\end{tabular}

\subsection{La-Rich Phase Identification}

In order to clarify the overall distribution of La in the Al-7Si alloy, EPMA equipped with WDS was used to observe the element distribution, and the results are shown in Figure 5. The large atomic number difference made compositional imaging possible, illustrating the brighter contrast of La-rich intermetallics, as shown in Figure 5a. These La-rich intermetallics were found to segregate strongly to the eutectic Si phase, and no significant enrichment of La in the primary Al phase was observed. They are marked with round white circles in Figure $5 \mathrm{~d}$. The size of La-rich intermetallics was about $0.5-1 \mu \mathrm{m}$. To determine the crystal structure and lattice parameter of La-rich intermetallics, TEM and EDS measurements were conducted.

As shown in the TEM analysis results in Figures 6 and 7, there were two kinds of La-rich intermetallics: some attached to the boundary of the eutectic Si particles (Figure 6) and some distributed in the eutectic phase (Figure 7). According to the selected electron diffraction patterns (SADP) shown in Figures $6 \mathrm{~b}$ and $7 \mathrm{~b}$, the crystal structure and lattice parameter of these La-rich intermetallics were determined to be hexagonal $(a=0.405 \mathrm{~nm}, \mathrm{c}=6.944 \mathrm{~nm})$, which was in very close agreement with that of $\mathrm{Al}_{2} \mathrm{Si}_{2} \mathrm{Yb}$ phase [19]. All the observed La-rich intermetallics were $\mathrm{Al}_{2} \mathrm{Si}_{2} \mathrm{La}$ phase based on the TEM and EDS analysis.
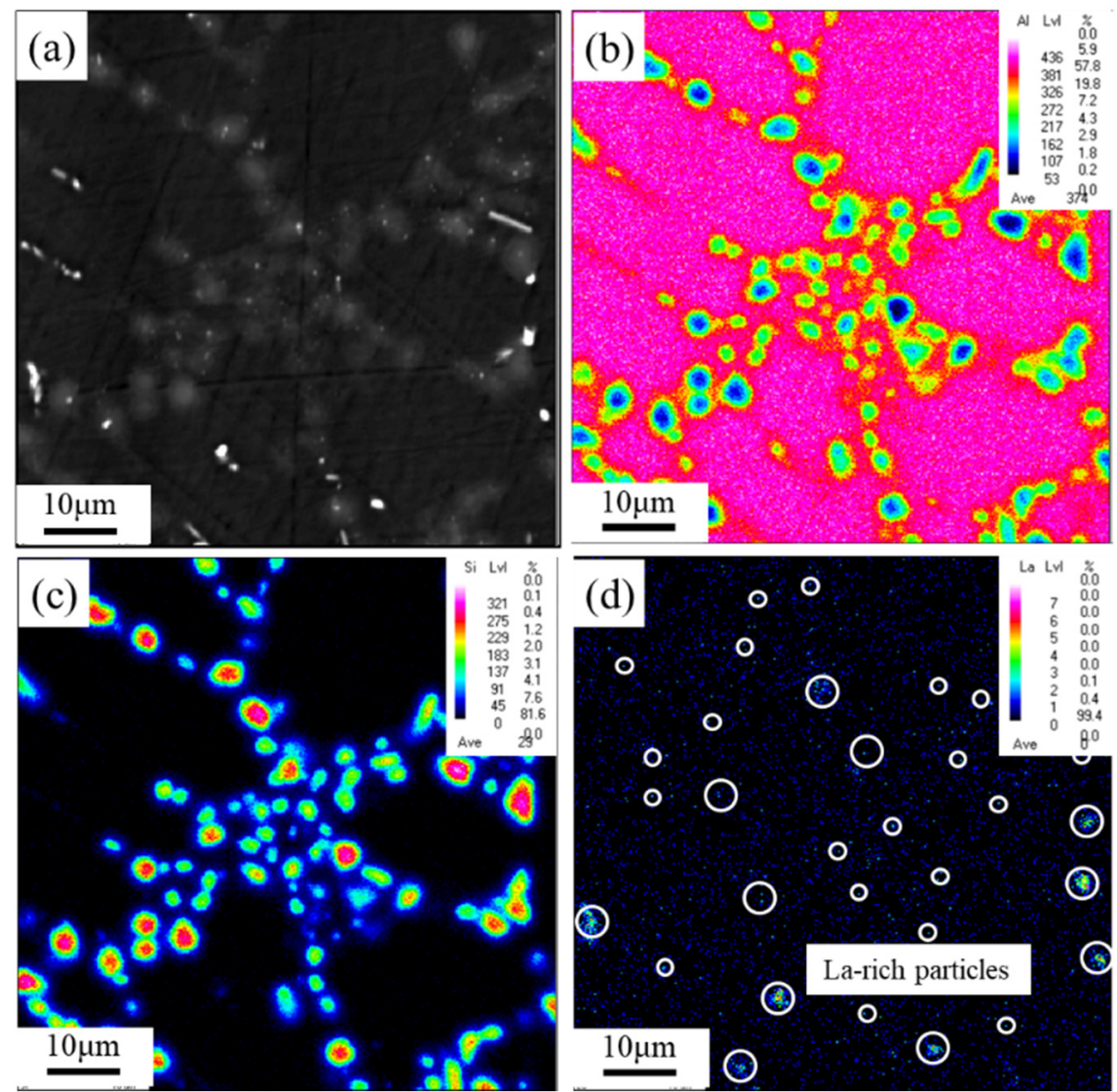

Figure 5. EPMA mappings of Al-7Si alloy with 0.1La addition: (a) back-scattered image; (b) Al element; (c) Si element; (d) La element. 


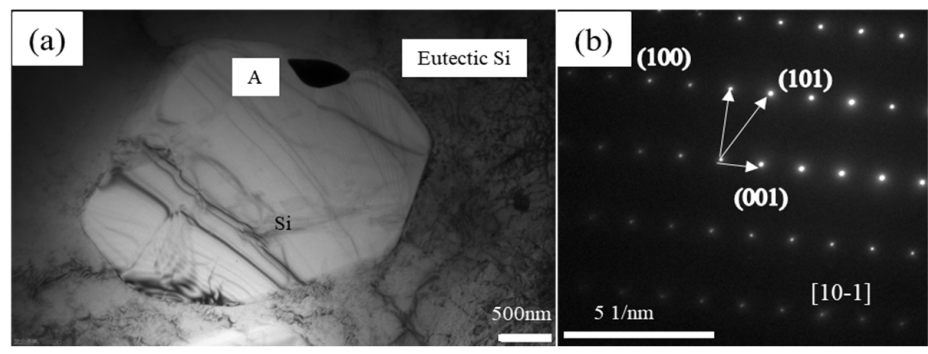

\begin{tabular}{ccc} 
(c) & & \\
\hline Element & wt.\% & wt.\% Sigma \\
\hline $\mathrm{Al}$ & 22.88 & 0.66 \\
$\mathrm{Si}$ & 17.79 & 0.59 \\
$\mathrm{La}$ & 59.33 & 0.88 \\
Total: & 100.00 & \\
\hline
\end{tabular}

Figure 6. (a) TEM bright-field images; (b) corresponding SADP of La-rich intermetallic in the eutectic Si particles; (c) weight fraction of point A.

(a)

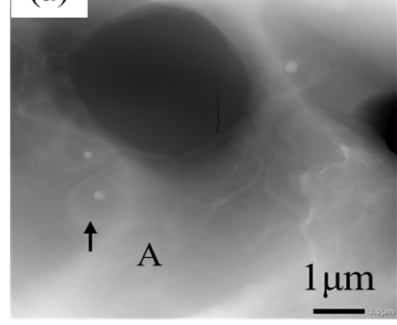

\section{(b)}

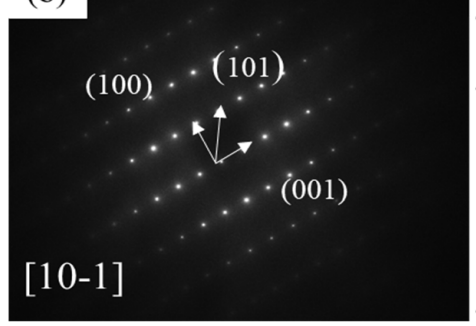

(c)

\begin{tabular}{ccc} 
Element & wt.\% & wt.\% Sigma \\
\hline $\mathrm{Al}$ & 80.89 & 0.31 \\
$\mathrm{Si}$ & 6.01 & 0.16 \\
$\mathrm{La}$ & 13.09 & 0.29 \\
Total: & 100.00 & \\
\hline
\end{tabular}

Figure 7. (a) TEM dark-field images of nano-sized La-rich intermetallics; (b) the corresponding SADP in the vicinity of eutectic Si particles; (c) weight fraction of point A.

\subsection{TEM Observation}

According to the microstructure analysis, the addition of La had the effect of refining eutectic Si particles rather than modifying them. In order to elucidate the refinement mechanism, two kinds of $\mathrm{Si}$ particles with round and rod-like shapes were observed. TEM of the Si particle tilted to the principal twinning orientation of $\mathrm{Si}<110>$ was conducted to observe twining [17-20], and the results are presented in Figure 8. Some surface artifacts caused by sample preparation were present on $\mathrm{Si}$ particles. It was evident that there was no La segregation and no twinning in the eutectic Si particles shown in Figure 8a,c. This indicates that the effect of La was different from the modification mechanism of $\mathrm{Sr}$ and $\mathrm{Na}$, although the rare earth element $\mathrm{La}$ had the perfect radius ratio to $\mathrm{Si}$ (1.604). It had a similar refinement effect on eutectic Si caused by the addition of other rare earth elements ( $\mathrm{Yb}$, Sc, etc.) as reported by authors in $[19,20]$.

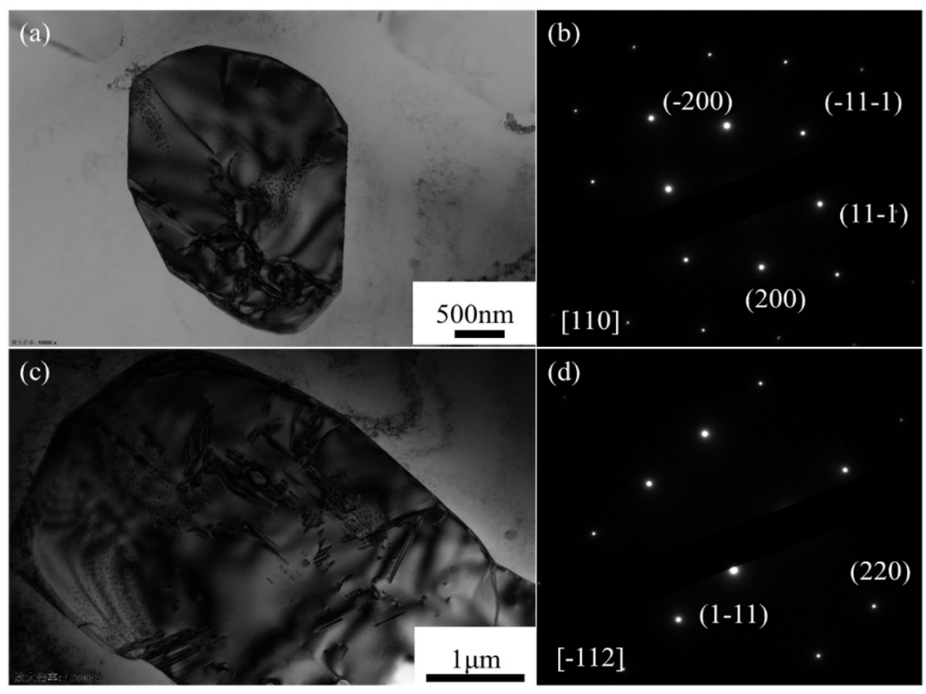

Figure 8. $(\mathbf{a}, \mathbf{c})$ TEM bright field images; $(\mathbf{b}, \mathbf{d})$ the corresponding SADP of the Si phase in Al-7Si-0.1La alloy. No clear Si twin was observed. 


\subsection{Multi-Refinement Mechanism of La}

As shown in Figure 4 and Table 3, the incorporation of 0.1 wt.\% La in Al-7Si alloy caused the reduction in $\alpha$-Al grain size by $26.8 \%$. However, it is also evident in Figure 5 that the La-rich intermetallic $\mathrm{Al}_{2} \mathrm{Si}_{2} \mathrm{La}$ phase was segregated strongly to the eutectic Si phase, and no significant enrichment of La-rich intermetallics in the primary Al was observed. In addition, during the solidification process, the formation of a $\mathrm{Al}_{2} \mathrm{Si}_{2} \mathrm{La}$ phase began below the solidus temperature of Al-Si alloy [24]. Therefore, the heterogeneous nucleation contribution of $\mathrm{Al}_{2} \mathrm{Si}_{2} \mathrm{La}$ phase was impossible.

It is well known that La has very limited solubility in aluminum [25]. The maximum La solid-solubility in $\alpha$-Al was found to be 0.05 at. $\%$ at $898 \mathrm{~K}\left(625^{\circ} \mathrm{C}\right)$. In the liquid state, the alloying elements were randomly distributed, although solute clustering may occur. During the solidification process, La was very easy to aggregate at the solid-liquid interface, as shown in Figure 9a, thus resulting in the constitutional undercooling in the diffusion layer. This constitutional undercooling stimulated the formation of the $\mathrm{Al}_{2} \mathrm{Si}_{2} \mathrm{La}$ phase along the boundaries and retarded the growth of $\alpha$-Al primary, eventually resulting in a further reduction in grain size. Therefore, the grain refinement of La in Al-7Si alloy can be explained by the growth-restricting factor (GRF) of the alloy, which increased when La was added to the alloy [21].

It has also been reported that the refinement of SDAS is due to the effect of rare earth elements on the solidification process [26,27]. SDAS was determined by the following equations [17]:

$$
\begin{gathered}
\lambda_{2}=5.5\left(M t_{f}\right)^{1 / 3} \\
M=\frac{\Gamma D \ln \left(C_{l}^{m} / C_{0}\right)}{m(1-k)\left(C_{0}-C_{l}^{m}\right)} \\
k=C_{s} / C_{L}
\end{gathered}
$$

where $\lambda_{2}$ is the value of SDAS, $\mu \mathrm{m} ; t_{f}$ is the local solidification time, $s ; \Gamma$ is the Gibbs-Thomson coefficient; $D$ is the diffusion coefficient in liquid, $\mathrm{m}^{2} \cdot \mathrm{s}^{-1} ; m$ is the liquid slope, $\mathrm{K} / \mathrm{wt} . \% ; C_{0}$ is the initial alloy concentration, wt. $\% ; C_{l}^{m}=$ Ce the eutectic composition, wt. $\%$; $k$ is the distribution coefficient; and $C_{s}$ and $C_{L}$ are the equilibrium solubility.

According to Equation (1), $\lambda_{2}$ was determined by $M$ and solidification time $t_{f}$. When the rare earth element La was added into the melt as a surface-active element, La concentrated at the front of the solid-fluid interface during the solidification process. Then, it blocked the diffusion of $\mathrm{Si}$, which increased the value of $C_{L}$ in the binary Al-Si system. Thus, the distribution coefficient $k$ decreased, leading to a decrease of $M$. As a result, the addition of La decreased the size of $\lambda_{2}$ in comparison with the unmodified alloy. Meanwhile, the concentration of Si and Mg solutes in the front liquid interface was reduced due to the concentration of La. The mitigation of the concentration gradient of the boundary diffusion layer resulted in a decrease in temperature gradient, which shortened the local solidification time. Consequently, the decreased $M$ and solidification time led to the decrease of SDAS, as presented in Figure 4, from $20.26 \mu \mathrm{m}$ to $18.66 \mu \mathrm{m}$ (decreased by $7.7 \%$ ) with the addition of 0.1 wt.\% La.

Contrasting with a previous report on the modification mechanism [28], no twins or La-rich phase was detected in eutectic Si particles in the Al-7Si alloy with $0.1 \mathrm{wt}$ \% La addition. The partitioning behavior and solute redistribution during the solidification process were of great importance in clarifying this refinement mechanism on eutectic Si particles. The schematic presentation is shown in Figure 9b. During eutectic Si growth, La and Al solute segregated ahead of the solidification interface $\left(\mathrm{k}_{\mathrm{Al}}<1\right.$ and $\left.\mathrm{k}_{\mathrm{La}}<1\right)$. Thereby, an enrichment of La and $\mathrm{Al}$ occurred. No $\mathrm{Al}_{2} \mathrm{Si}_{2} \mathrm{La}$ particle was observed within eutectic Si because no significant solute adsorption and entrapment of La atoms occurred during eutectic $\mathrm{Si}$ growth. Instead, most $\mathrm{Al}_{2} \mathrm{Si}_{2} \mathrm{La}$ particles were observed adjacent to the $\mathrm{Si}$ phase, which strongly indicated that most La atoms segregated out of eutectic $\mathrm{Si}$, as presented in the schematic in Figure 9b. La atoms distributed on Si and dendrite surfaces at the solidification interface front 
acted as obstacles. Meanwhile, the diffusion and exchange of the solutes were inhibited, resulting in slower solute accumulation on the Si surface and the decrease of constitutional undercooling. Finally, the growth rate of eutectic $\mathrm{Si}$ was slowed down, and coordinated growth between $\mathrm{Al}$ and $\mathrm{Si}$ was achieved. In addition, the $\mathrm{Al}_{2} \mathrm{Si}_{2} \mathrm{La}$ phase that appeared after the formation of the Si phase also promoted the heterogeneous nucleation of eutectic Si particles. This refinement mechanism caused by the growth-restricting factor was different from the well-known impurity-induced twinning (IIT) and twin plane re-entrant edge (TPRE) modification mechanisms. Therefore, it is preferable to state that the effect of La on eutectic Si was as a refiner, rather than a modifier.

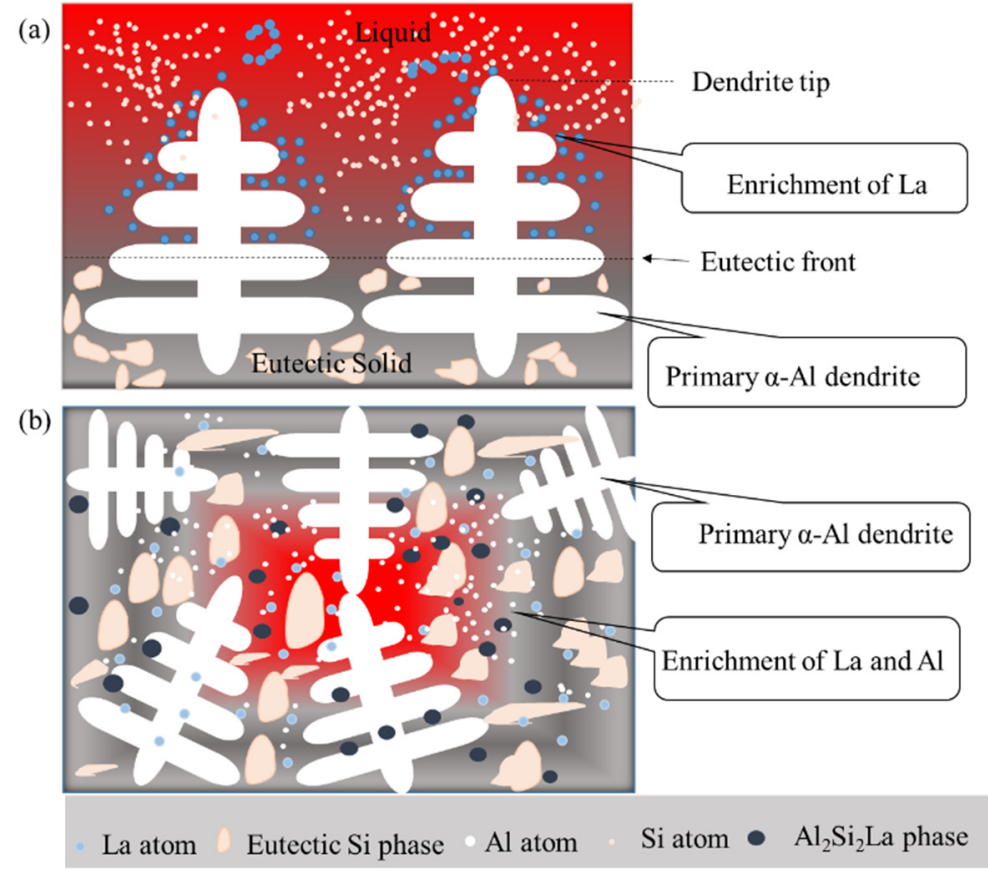

Figure 9. Schematic of multi-refinement of rare earth La on Al-7Si alloy: (a) solidification of primary $\alpha-\mathrm{Al} ;(\mathbf{b})$ solidification of eutectic $\mathrm{Si}$ and $\mathrm{Al}_{2} \mathrm{Si}_{2} \mathrm{La}$.

\section{Conclusions}

A detailed investigation was conducted in this work to determine the effects of La on the microstructures of Al-7Si alloys and to analyze the systematic refinement mechanism. Based on the results obtained, the main conclusions can be summarized as follows.

(1) The addition of $0.1 \mathrm{wt} . \% \mathrm{La}$ to Al-7Si alloys resulted in a very good multi-refinement effect on primary $\alpha$-Al grain size and eutectic Si particles. The $\alpha$-Al grain size, secondary dendrite arm spacing and area of eutectic Si particles were decreased by $26.8 \%, 7.7 \%$ and $26.7 \%$, respectively.

(2) The multi-refinement of La on grain size, eutectic Si particles and dendrite structure was due to the growth-restricting factor and constitutional undercooling caused by the low solubility of La in Al alloy.

(3) The small La-rich phase distributed in the vicinity of eutectic Si particles, which was believed to inhibit the growth of eutectic $\mathrm{Si}$ particles. These particles were proved to be $\mathrm{Al}_{2} \mathrm{Si}_{2} \mathrm{La}$ phase, and their crystal structure and lattice parameter were hexagonal with $\mathrm{a}=\mathrm{b}=0.405 \mathrm{~nm}, \mathrm{c}=6.944 \mathrm{~nm}$.

Author Contributions: Conceptualization, H.Z. (Hu Zhang) and H.Z. (Huarui Zhang); methodology, X.W.; validation, H.Z. (Hu Zhang) and H.Z. (Huarui Zhang); formal analysis, X.W.; investigation, X.W.; resources, X.W.; data curation, X.W.; writing-original draft preparation, X.W.; writing-review and editing, H.J., Z.M.; supervision, H.J., Z.M. and H.Z. (Huarui Zhang); funding acquisition, X.W. All authors have read and agreed to the published version of the manuscript.

Funding: This work was supported by the Fundamental Research Funds for the Central Universities [grant numbers FRF-TP-19-083A1] and the Aviation Science Foundation Project [grant numbers 20181174001]. 
Conflicts of Interest: The authors declare no conflict of interest.

\section{References}

1. Wu, X.; Zhang, H.; Ma, Z.; Jia, L.; Zhang, H. Effect of Holding Pressure on Microstructure and Mechanical Properties of A356 Aluminum Alloy. J. Mater. Eng. Perform. 2018, 27, 483-491. [CrossRef]

2. Wu, X.; Yun, Y.; Zhang, H.; Ma, Z.; Jia, L.-N.; Tao, T.; Zhang, H. Effect of holding pressure on microstructure and fracture behavior of low-pressure die cast A356-T6 alloy. Mater. Res. Express 2017, 4, 126501. [CrossRef]

3. Wu, X.; Zhang, H.; Chen, H.-L.; Jia, L.-N.; Zhang, H. Evolution of microstructure and mechanical properties of A356 aluminium alloy processed by hot spinning process. China Foundry 2017, 14, 138-144. [CrossRef]

4. Jiang, W.; Fan, Z.; Liao, D.; Liu, D.; Zhao, Z.; Dong, X. Investigation of microstructures and mechanical properties of A356 aluminum alloy produced by expendable pattern shell casting process with vacuum and low pressure. Mater. Des. 2011, 32, 926-934. [CrossRef]

5. Jiang, W.; Fan, Z.; Liu, D.; Liao, D.; Dong, X.; Zong, X. Correlation of microstructure with mechanical properties and fracture behavior of A356-T6 aluminum alloy fabricated by expendable pattern shell casting with vacuum and low-pressure, gravity casting and lost foam casting. Mater. Sci. Eng. A 2013, 560, $396-403$. [CrossRef]

6. Birol, Y. Impact of grain size on mechanical properties of $\mathrm{AlSi}_{7} \mathrm{Mg}_{0.3}$ alloy. Mater. Sci. Eng. A 2013, 559, 394-400. [CrossRef]

7. Lee, C. Effect of Ti-B addition on the variation of microporosity and tensile properties of A356 aluminium alloys. Mater. Sci. Eng. A 2016, 668, 152-159. [CrossRef]

8. Zhao, H.; Bai, H.; Wang, J.; Guan, S. Preparation of Al-Ti-C-Sr master alloys and their refining efficiency on A356 alloy. Mater. Charact. 2009, 60, 377-383. [CrossRef]

9. Timelli, G.; Caliari, D.; Rakhmonov, J. Influence of Process Parameters and Sr Addition on the Microstructure and Casting Defects of LPDC A356 Alloy for Engine Blocks. J. Mater. Sci. Technol. 2016, 32, 515-523. [CrossRef]

10. Hegde, S.; Prabhu, K.N. Modification of eutectic silicon in Al-Si alloys. J. Mater. Sci. 2008, 43, 3009-3027. [CrossRef]

11. Li, Q.; Li, B.; Li, J.; Zhu, Y.; Xia, T. Effect of yttrium addition on the microstructures and mechanical properties of hypereutectic Al-20Si alloy. Mater. Sci. Eng. A 2018, 722, 47-57. [CrossRef]

12. Li, Q.; Xia, T.; Lan, Y.; Li, P.; Fan, L. Effects of rare earth Er addition on microstructure and mechanical properties of hypereutectic Al-20\% Si alloy. Mater. Sci. Eng. A 2013, 588, 97-102. [CrossRef]

13. Wan, B.; Chen, W.; Liu, L.; Cao, X.; Zhou, L.; Fu, Z. Effect of trace yttrium addition on the microstructure and tensile properties of recycled Al-7Si-0.3Mg-1.0Fe casting alloys. Mater. Sci. Eng. A 2016, 666, 165-175. [CrossRef]

14. Colombo, M.; Gariboldi, E.; Morri, A. Er addition to Al-Si-Mg-based casting alloy: Effects on microstructure, room and high temperature mechanical properties. J. Alloys Compd. 2017, 708, 1234-1244. [CrossRef]

15. Xu, C.; Xiao, W.; Hanada, S.; Yamagata, H.; Ma, C. The effect of scandium addition on microstructure and mechanical properties of Al-Si-Mg alloy: A multi-refinement modifier. Mater. Charact. 2015, 110, 160-169. [CrossRef]

16. Røyset, J.; Ryum, N. Scandium in aluminum alloys. Int. Mater. Rev. 2013, 50, 19-43. [CrossRef]

17. Qiu, H.; Yan, H.; Hu, Z. Effect of samarium (Sm) addition on the microstructures and mechanical properties of Al-7Si-0.7Mg alloys. J. Alloys Compd. 2013, 567, 77-81. [CrossRef]

18. Lu, S.-Z.; Hellawell, A. The mechanism of silicon modification in aluminum-silicon alloys: Impurity induced twinning. Met. Mater. Trans. A 1987, 18, 1721-1733. [CrossRef]

19. Li, J.H.; Suetsugu, S.; Tsunekawa, Y.; Schumacher, P. Refinement of Eutectic Si Phase in Al-5Si Alloys with Yb Additions. Met. Mater. Trans. A 2012, 44, 669-681. [CrossRef]

20. Li, J.; Wang, X.; Ludwig, T.; Tsunekawa, Y.; Arnberg, L.; Jiang, J.; Schumacher, P. Modification of eutectic Si in Al-Si alloys with Eu addition. Acta Mater. 2015, 84, 153-163. [CrossRef]

21. Pourbahari, B.; Emamy, M. Effects of La intermetallics on the structure and tensile properties of thin section gravity die-cast A357 Al alloy. Mater. Des. 2016, 94, 111-120. [CrossRef]

22. Bin Ahmad, R.; Asmael, M. Influence of Lanthanum on Solidification, Microstructure, and Mechanical Properties of Eutectic Al-Si Piston Alloy. J. Mater. Eng. Perform. 2016, 25, 2799-2813. [CrossRef] 
23. Wang, T.; Zhao, Y.; Chen, Z.; Zheng, Y.; Kang, H. The bimodal effect of La on the microstructures and mechanical properties of in-situ A356-TiB2 composites. Mater. Des. 2015, 85, 724-732. [CrossRef]

24. Chang, J.; Kim, G.; Moon, I.; Choi, C. Rare earth concentration in the primary Si crystal in rare earth added Al-21wt.\%Si alloy. Scr. Mater. 1998, 39, 307-314. [CrossRef]

25. Hosseinifar, M.; Malakhov, D.V. The Sequence of Intermetallics Formation during the Solidification of an Al-Mg-Si Alloy Containing La. Met. Mater. Trans. A 2010, 42, 825-833. [CrossRef]

26. Xiaoyan, W.; Huarui, Z.; Feng, J.; Ying, Y.; Lina, J.; Hu, Z. Microstructure and Grain Refinement Performance of a New Al-5Nb-RE-B Master Alloy. Rare Met. Mater. Eng. 2018, 47, 2017-2022. [CrossRef]

27. El Sebaie, O.; Samuel, A.; Samuel, F.H.; Doty, H. The effects of mischmetal, cooling rate and heat treatment on the eutectic Si particle characteristics of A319.1, A356.2 and A413.1 Al-Si casting alloys. Mater. Sci. Eng. A 2008, 480, 342-355. [CrossRef]

28. Samuel, A.; Doty, H.; Valtierra, S.; Samuel, F.H. Effect of grain refining and Sr-modification interactions on the impact toughness of Al-Si-Mg cast alloys. Mater. Des. 2014, 56, 264-273. [CrossRef]

(C) 2020 by the authors. Licensee MDPI, Basel, Switzerland. This article is an open access article distributed under the terms and conditions of the Creative Commons Attribution (CC BY) license (http://creativecommons.org/licenses/by/4.0/). 